\title{
Designing Sustainable Gabion Houses for Haiti Using Local Resources
}

\author{
April E. Simons, Heath Barton² and Ryan Logan ${ }^{3}$
}

1 Auburn University, Auburn, USA, ellisap@auburn.edu

2 Auburn University, Auburn, USA, jhb0051@tigermail.auburn.edu

3 Auburn University, Auburn, USA, rel0035@tigermail.auburn.edu

\begin{abstract}
Many concrete masonry unit (CMU) block homes have been constructed recently in Thoman, Haiti using volunteer labor under the supervision of But God Ministries. The average cost of construction is $\$ 5,000$ per home and is dependent on availability and willingness of volunteer labor. Thoman's landscape is covered in loose rocks, largely due to dried up river beds. A sustainable home design which utilizes this abundantly available resource could drive down construction cost and reduce the need for volunteer labor. Gabion walls are wirework containers filled with rock or rubble. Though they are typically used in the construction of dams and retaining walls, they have successfully been used to construct other various structures including structural foundations (Liu, 2012), commercial construction (Conti, 2016) and residential applications in developing countries (Potangaroa, 2013). This research includes the physical construction of an L-shaped wall to determine the effectiveness and feasibility of constructing gabion homes in Thoman, Haiti. The physical wall model consists of a 2 -foot wide by 6 -inch deep concrete foundation, 8-foot tall wall cages of 10-gauge concrete reinforcing mesh with 6-inch by 6 -inch openings, No. 1 aggregate wall infill, and stucco finish on both sides. The total length of wall is 16 -feet, with one 10-foot leg and one 6-foot leg. Scaled models of three different roof structures were constructed and analyzed to determine which material systems would best serve the intended purpose for the gabion home design. The roof systems tested include wood frame, angle iron frame, and PVC frame, each of which was topped with corrugated metal roof panels. Two methods were tested for airflow which include corrugated plastic panels and mesh screens. The research findings suggest that chicken wire should be added to the proposed design to serve as a liner for the gabion baskets. The added wire helps secure smaller river rock and provides additional surface area for stucco adherence. The recommended cement to sand mixture for stucco was found to be 1:1. The angle iron framed roof proved to be the most effective of the three roof systems tested because of its availability, strength, and durability. Finally, the mesh screens were chosen to be the most effective roof ventilation method as it was shown to provide more airflow through the structure. Future research should analyze the strength and lifecycle of the final proposed design and evaluate alternate roof systems.
\end{abstract}

(c) 2020 The Authors. Published by Budapest University of Technology and Economics \& Diamond Congress Ltd Peer-review under responsibility of the Scientific Committee of the Creative Construction Conference 2020.

Keywords: gabion, rubble, house, sustainability

\section{Introduction}

The January 12, 2010 Haiti earthquake destroyed almost 20\% of the buildings in Port-au-Prince and killed nearly 250,000 people. While the earthquake is not categorized as "great" from seismic standards, its damages rank it as one of the deadliest earthquakes of the $21^{\text {st }}$ Century [1]. The reasoning for such extensive damage from this earthquake stems from the fact that Haiti is the poorest country in the Americas and a majority of homes are self-constructed and not built to any seismic codes [2]. An estimated $89 \%$ of 
the fatalities in Haiti resulted from faulty building construction, such as the use of masonry without any reinforced steel [2]. Evidence suggests that the earthquake would not have been so devastating if proper construction techniques had been applied. For example, the U.S. Embassy in Haiti was constructed with concrete walls and only suffered minor damages [2].

Thoman, Haiti is a rural village just 50 miles east of Port-au-Prince. Currently, CMU block housing is the predominant type of house being built by volunteers with But God Ministries. The average cost to build CMU block house is roughly $\$ 5,000$ and volunteers typically travel down to Thoman to build it. There is a strong need for this research because Thoman's landscape is covered in loose rocks that would be the perfect natural resource for a gabion wall house. Gabion walls are wirework containers filled with rock or rubble and are typically used in the construction of retaining walls. A sustainable, repeatable house design that utilizes the loose rock abundantly available in Thoman could drastically decrease the cost to construct homes for Thoman residents and minimize the dependency on American volunteers to build houses in the region.

\section{Literature review}

\subsection{Introduction}

A gabion is a wire cage filled with rocks or rubble and is typically used in the construction of retaining walls for erosion control. The cages can be vertically continuous or shorter and stacked on top of each other to form a wall [3]. Gabions can vary in thickness depending on their intended use and the cages can either have a polygonal net or a rectangular net. The idea of modifying the design of traditional gabions to expand their applications beyond retaining walls is not a new one. Gabions have previously been used in structural foundations, commercial construction, and residential construction in developing countries.

\subsection{Sustainable housing and construction}

Sustainable housing offers both environmental and financial benefits that are supported in research, both quantitatively and qualitatively. Some of these benefits include better construction materials available for construction, savings that outweighed the cost of buying sustainable appliances vs. unsustainable appliances current cost, a better payback period in regards to sustainable techniques, and the ability for sustainable housing to be built under controlled costs [4]. Many of the characteristics that gabion cages have make them very good options for sustainable housing in developing countries. They are durable, require no power tools for modification, utilize natural resources, and they can be built using an unskilled labor force. When it comes to sustainability, the steel of the gabion cages is expensive in terms of the energy used in its production and recycling processes, but the material itself can be recycled many times.

\subsection{Previous work}

Previous research shows that the use of gabion cages has been explored for various construction uses in underdeveloped areas, including the places listed below. Interviews were conducted with a representative involved in construction for each individual location to ascertain best practices and lessons learned.

- Nepal - Rubble from destroyed buildings was used to fill cages and rebuild structures after earthquakes [5].

- Grande Goav, Haiti - River rock from dried up river beds was used to fill cages and construct houses after the 2010 earthquake [6].

- Lilavois, Haiti - Crushed rubble was used to fill cages and construct houses as part of disaster response after earthquake devestation [7].

- Port-au-Prince, Haiti - Researchers at Kennesaw State University developed a gabion house design and built a prototype on campus then implemented the design in Port-au-Prince [8].

Although great information was gleaned from all three of the interviews listed above, the research conducted at Kennesaw State University [8] produced a detailed design that simply needed refinement to adapt the structure for use in Thoman. 


\subsection{Design considerations}

With there being no form of electricity in rural villages of Haiti to combat hot climate in the warmer months, it is imperative that the gabion house be designed in a way that promotes natural airflow. This aspect of the design will be a collaboration between the roof and the walls of the house. Key openings that facilitate airflow need to be established on the walls and openings to promote circulation as well as improve air quality and indoor air temperature. Previous research analyzed the natural ventilation quality of a traditional Malay house by measuring temperature, humidity, and wind speed of the house [9]. The results stated that the indoor temperature and relative humidity was lower than the outdoors, indicating that having maximum openings on the walls of the house leads to high air intakes and puts an emphasis on cross air ventilation.

Aside from openings, there are novel ways for roof designs to promote ventilation. A previous study focused on the effect of solar chimneys inclination rate on air ventilation rates [10]. This study measured exit air velocity at increasing inclination angles and determined that the optimal angle is between 45 and 75 degrees. Another discovery was that air reached deeper into the interior room as the inclination angle increased. While a solar chimney would be an effective way to promote ventilation, the scope of this research limits the amount of available resources and including a solar chimney in the design of the gabion house is impractical.

\section{Research methodology}

A methodology was formulated based on the knowledge gained from the literature review. The published research on gabion houses and the interviews conducted were used to formulate a basic gabion house designs and 3 basic roof designs for testing. The research proceeded in the following steps.

- Create basic design drawings of gabion house

- Construct gabion wall prototype

- Construct 3 roof prototypes for comparison

SketchUp was the primary tool used to create design drawings. While there is an abundance of online design software available, many products require the user to purchase a license. The fact that SketchUp is free is important since the future users of the drawings will include non-profit organizations and volunteer organizations. Additionally, the design itself was simplistic, so complex programs like Revit were not necessary for this project. The preliminary design is shown in Figure 1, below.
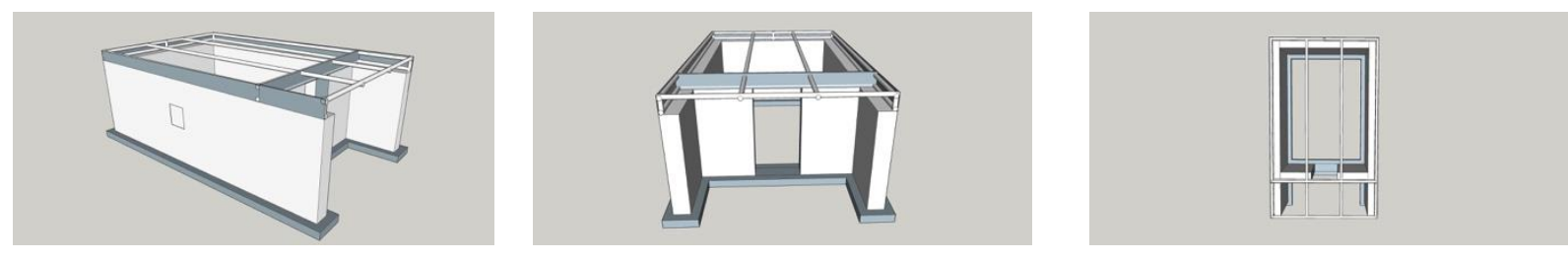

Figure 1: Sketchup model of Gabion House

The physical construction of a portion of the gabion house was completed at the McWhorter School of Building Science (BSCl) field lab on Auburn University's campus. Different fill materials and methods were compared and the design's foundation system was analyzed. A corner of the proposed design (L-shaped wall) was constructed. Construction of an L-shaped wall rather than a full-scale model allowed a reduced cost and complexity while providing a sufficiently detailed analysis of the proposed wall design.

Three roof prototypes were also constructed at Auburn University's BSCI field lab. The first roof model analyzed was a wooden roof frame which was chosen for its simple design. The concern for this model is that wood is not readily available in Haiti, so it may be difficult to implement this system in the village of Thoman. The second model tested was a single-slope PVC pipe frame which was chosen for its ease of 
construction. The third roof prototype built was an angle iron roof frame due to its perceived strength and material longevity.

\section{Results and discussion}

\subsection{Foundation}

The extensive interview with Fatih Oncul at Kennesaw State University [8] was the strongest influence on the design and construction of the foundation for the L-shaped wall. The wall's final foundation design was 6-inches wider than the wall on each side, making its total width 2 -ft with a depth of approximately 6 -inches. The concrete mix consisted of 1 part Portland cement, 2 parts sand, 3 parts aggregate, and water. To mimic the resources that would be available in Thoman, Haiti, the concrete was mixed with a shovel with a wheelbarrow by hand and poured into the footing. As the concrete was poured, two j-hooks of \#4 rebar were placed on the 10-foot wall and one was placed along the 6-foot wall. A level was also used to periodically check if the foundation was level between the rebar reference points.

\subsection{Wall cages}

The cages used for wall framing were constructed by hand with wire cutters and pliers from a 5 -ft $\times 150-\mathrm{ft}$ roll of 10-gauge concrete reinforcing mesh with 6-inch $\times$ 6-inch openings. Two 6-ft tall cages were constructed for the L-shaped wall; one was 10-ft in length and the other was 5 - $\mathrm{ft}$ in length. Both cages had cross bracing every $1-\mathrm{ft}$ which created $1-\mathrm{ft} \times 1-\mathrm{ft}$ columns. In order to assemble the cages, the wall panels were cut to their appropriate dimensions with 3 inches of wire left on all sides so they could be bent around to secure the pieces together. For the $10-\mathrm{ft}$ wall, two panels, 5 -ft each in length, had to be connected together by laying a $1-\mathrm{ft}$ width panel over the seam of the two 5 -ft panels and then bending the wires around to connect them. Before assembling the panels together, chicken wire was placed on the interiors of the panels to prevent smaller rock from spilling out of the cage openings. Additionally, tie wire was placed on both ends of the L-shaped wall. It was zig-zagged down from the top of the cage and provided the wall with additional lateral strength. The tie wire was also used to connect the two separate pieces of the L-shaped wall; tie wire was wrapped around the interior and exterior connection points of the two wall segments. Figure 2 provides visual representation of the gabion walls gages resting on the hand-mixed concrete foundations.
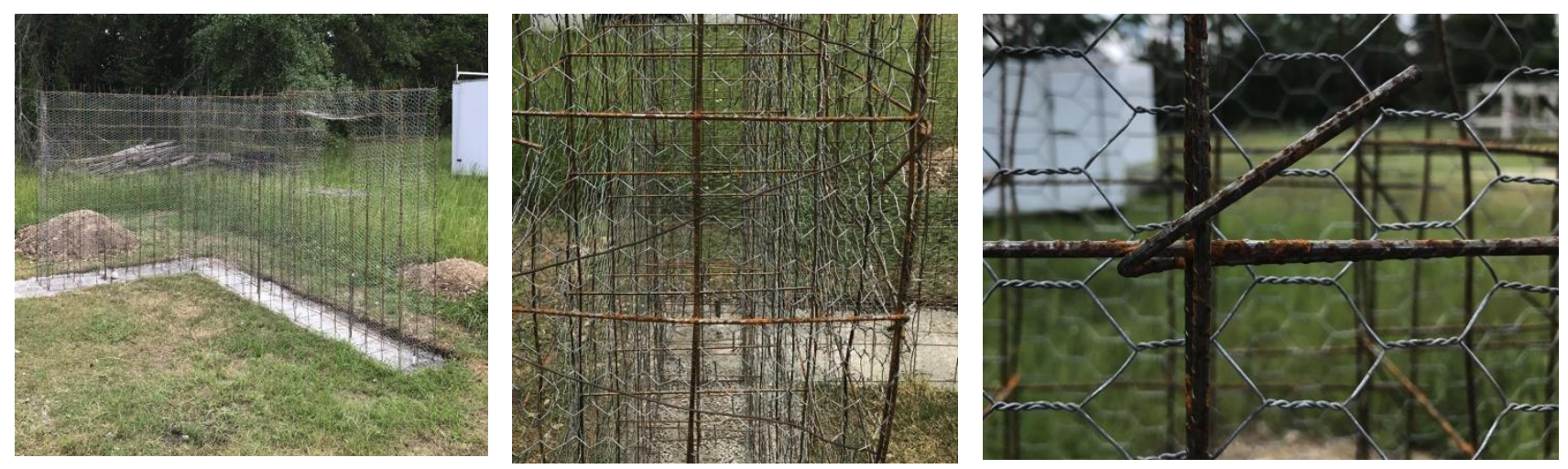

Figure 2: Foundation \& Wall Cages

\subsection{Cage fill and stucco}

The gabion wall cages were filled with \#1 aggregate from Martin Marietta Quarry in Auburn, AL. This aggregate was selected to mimic the approximate size range of river rock near Thoman, Haiti. The aggregate size ranged from as small as a golf ball to as large as a softball. Previous research utilized concrete rubble to fill the gabion baskets [8]. It was noted that the river rock in Thoman are much more dense than the aforementioned concrete rubble. To prevent bulges in the gabion wall baskets due to this extra weight from the river rock infill as opposed to concrete rubble, only every other column was filled with rock initially.

While attempting to fill only every other column with the aggregate, it was discovered that chicken wire needed to be placed against the cross-bracings to prevent the rocks from spilling into the adjacent columns. The rocks spilled through the opening which resulted in a slower fill process and every column ended up 
being filled at least 3 feet high. Through some trial and error, the most efficient fill process was filling a bucket with river rock and then dumping them into a cage column, but additional chicken wire on the cross bracings would significantly accelerate the process in the future.

The design included a concrete stucco on both sides of the wall to strengthen the structure and promote water resistance. A 50/50 mixture of Portland cement and sand with water proved to be the best consistency of mix to stucco the cages. The mixture adhered easily to the structure and eliminating gravel from the mix gave it a more refined finish. Only part of the L-shaped wall was covered in stucco due to budget limitations of the research, however, the full design provides a fully-stuccoed finish on all surfaces. Additionally, construction of the mock-up wall revealed that in order for the entire house to be stuccoed, all of the cages must be filled with river rock or a material other than chicken wire must be used to allow the stucco to fully adhere to the structure. Figure 3 shows the rock-filled wall cages as well as the partial stucco application.
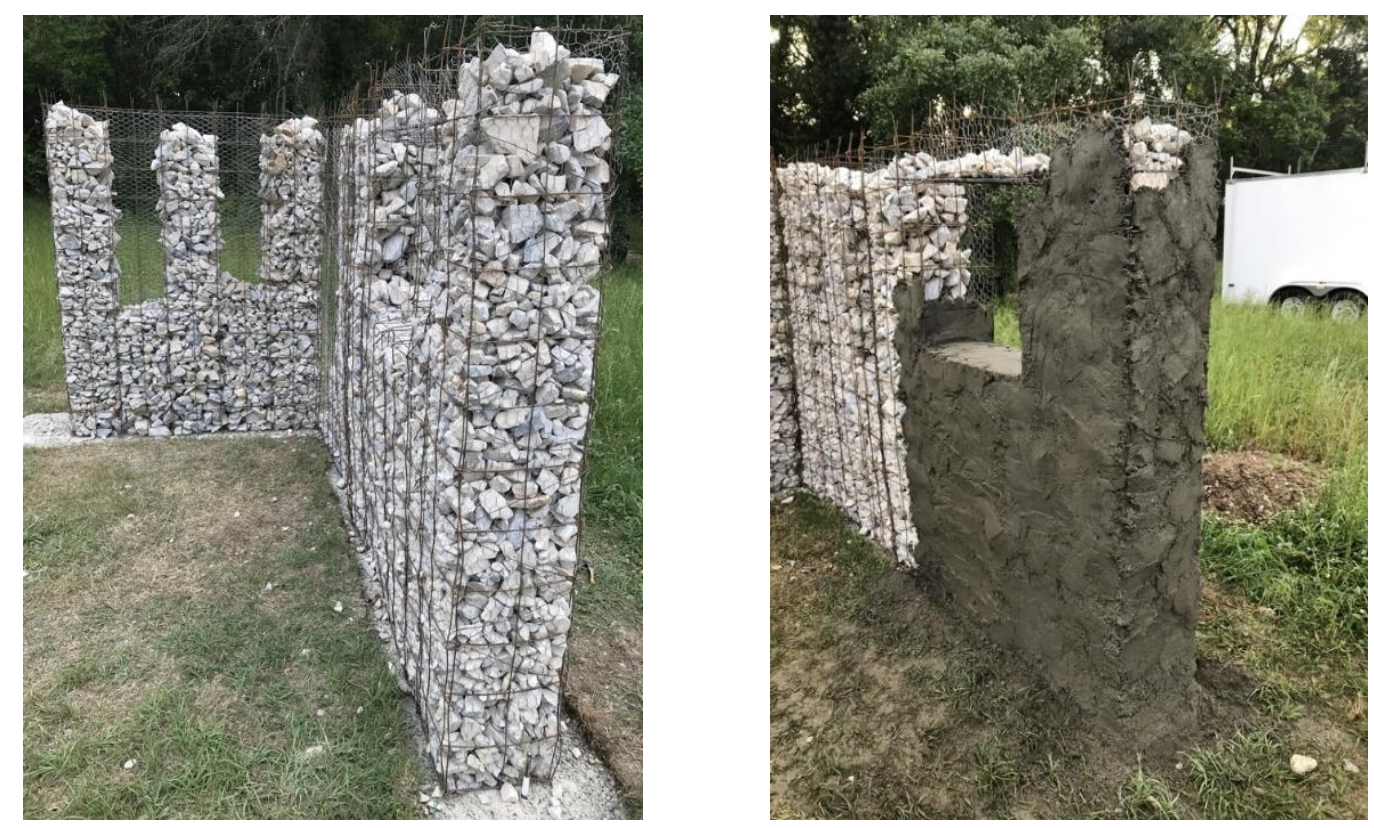

Figure 3: Filled Wall Cages

\subsection{Windows}

The inclusion of a window into this wall was simpler than originally anticipated. The design called for two 2 -ft $\times 2$-ft square windows to allow ventilation and natural air flow through the proposed structure. To test constructability of this design, a window was incorporated into the L-shaped wall. In order to prevent sagging of the top of the window, five pieces of \#4 rebar were laid across the opening and extended further than the window's width on either side. The space above the window opening was filled with river rock. Figure 4 shows the window frame details. 

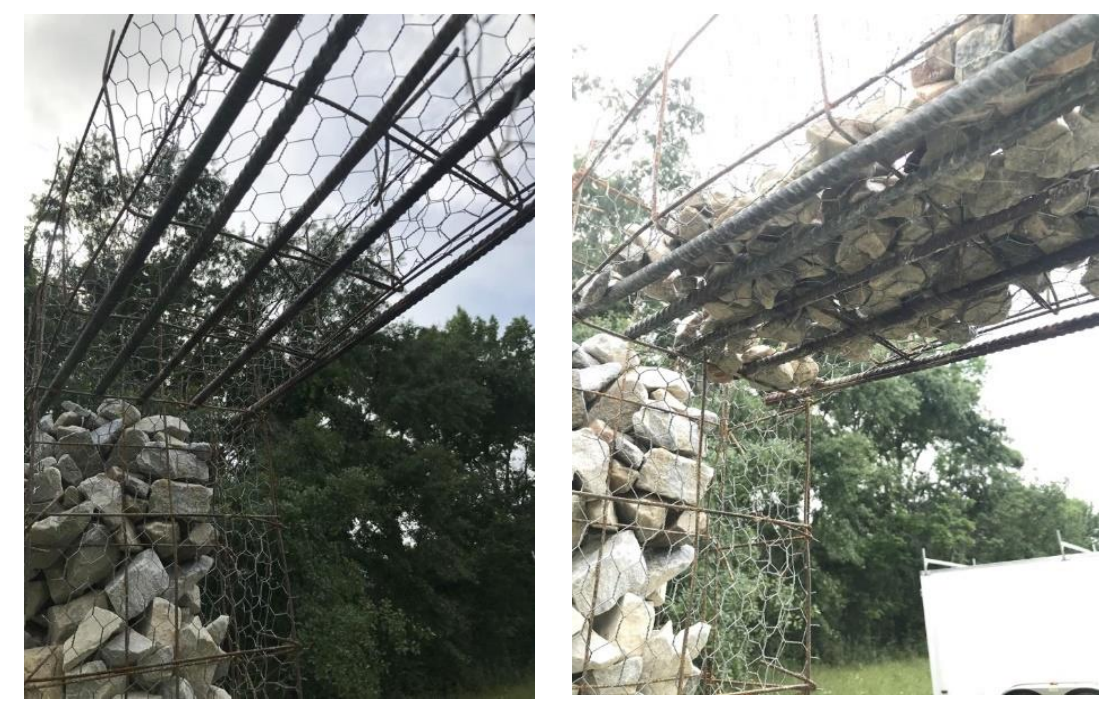

Figure 4: Window Opening

\subsection{Roof}

Each of the three roof prototypes constructed were built at a $1 / 4$ scale. The first roof model constructed was a wood-framed structure built at a 1 in 12 slope. After the wooden frame was complete, a simple metal roofing panel was attached to the top. Corrugated plastic panels with ventilation holes were added to the sides of the frame to complete this prototype. The total cost of materials for the wood-framed prototype was $\$ 48.92$.

The angle iron roof consisted of a single-sloped roof with a slope of 1 in 12 . The structure was made entirely of angle iron with an overhang of 8.75-inches on the front and back end of the roof and 13-inches on either side. The lengths of overhang with this design were flexible measurements in order to adjust for error during construction and to minimize waste. A metal roofing panel was added to the top. Although no gable ventilation was provided, the proposed ventilation for this model consists of corrugated plastic, similar to the wood-framed model. The total cost of materials for the angle iron-framed prototype was $\$ 278.04$.

The basic design of the PVC pipe roof frame is similar to the wood and angle iron systems. The PVC pipes were pieced together with connectors and adhered with all-purpose cement. A simple metal roofing panel was attached to the top of the PVC frame while meshing was added to the sides to provide ventilation. The total cost of materials for the PVC pipe-framed prototype was $\$ 133.65$.

Figure 5 shows the completed frames for each of the three roof prototypes built. Though the wood-framed prototype was the least expensive and simplest to construct, the availability of wood in Thoman is limited and the susceptibility of the material to rot is troublesome. The PVC pipe-framed prototype proved to have limited strength and was more complex to construct than the wood frame. Although the angle iron-framed prototype was the most expensive of the three, its inherent strength and durability make it a viable choice for the final recommended design.

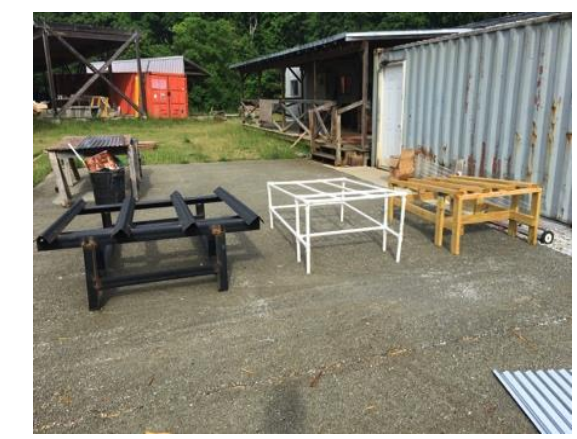

Figure 5: Iron, PVC, and Wood Roof Prototypes 


\section{Conclusions and recommendations}

The research presented herein indicates that a gabion house is a legitimate alternative to the current CMU block houses being built in Thoman, Haiti. The feasibility of the gabion design is dependent on future tests to determine is the cages are strong enough to support the river rock that is found in Haiti. If the cages can be completely filled with the local Thoman river rock without bulging or breaking, then the gabion house model could prove to be a better financial option than the CMU block houses currently being built in the region.

After constructing multiple scaled roof models with different materials, angle iron is the recommended roofing material because if its availability, strength, and durability. While wood would typically be the first choice because if its simplicity, workability, and economy, its lack of availability in Haiti makes it less desirable for this application. PVC was very easy to assemble, but the strength of the material and connections is lacking compared to angle iron or wood. One of the disadvantages to angle iron, as discussed in chapter 4, was the difficulty that came with welding. For the roof system to be assembled onsite, welding equipment and experience welders would need to be present in Haiti.

Two options were tested for airflow: mesh screening and clear plastic corrugated paneling. The mesh screening is the recommended for this application as it was found to provide the most airflow which will lower the indoor thermal temperature in the Haitian houses which typically do not have Heating, Ventilation, and Air Conditioning (HVAC) systems.

Future research should consist of quantitative experiments to analyze the exact strength and life cycle of the materials and design proposed herein. Additionally, qualitative experiments should be conducted to determine the ease of implementation of the proposed wall and roof designs within the community in Thoman, Haiti. This future research should assess the availability of welders and angle iron in Thoman to determine the feasibility of using the proposed roof design. Finally, future research should include a detailed construction cost analysis of the proposed design as compared to other methods currently used in the region of Thoman.

\section{References}

[1] R.T. Eguchi, G. Stuart, G. Shubharoop, S. Walter, E. Galen, T. Joaquin, A comprehensive assessment of building damage after the january 12, 2010 Haiti Earthquake, Electron. Structural Congress (2011) 11-37. https://doi.org/10.1061/41171(401)202.

[2] B. Raul, Great 2010 American earthquakes: lessons for seismic design and construction, J. Constr. Eng. Manag. 140, B4013003. https://doi.org/10.1061/(ASCE)CO.1943-7862.0000697

[3] H. Brennan, C. Howe, R. Matter-Neri, R. Potangarosa, The gabion house approach, Electron., https://iiirr.ucalgary.ca/files/iiirr/85.pdf

[4] J. Coimbra, M. Almeida, Challenges and benefits of building sustainable cooperative housing. Building and Environment (2013) 62 , 9-17. https://doi.org/10.1016/j.buildenv.2013.01.003

[5] P. Ghimire, 2018. Personal interview.

[6] E. Lynn, 2018. Personal interview.

[7] R. Potangaroa, The gabion house revisited. Journal of Architecture and Environment, v.12, n.1, 2013. https://core.ac.uk/download/pdf/70768082.pdf

[8] F. Oncul, 2018. Personal interview.

[9] A. Hassan, M. Ramli, Natural ventilation of indoor air temperature: a case study of the traditional Malay House in Penang, 2010. https://doi.org/10.3844/ajeassp.2010.521.528

[10] R. Bassiouny, N. Korah, Effect of solar chimney inclination angle on space flow pattern and ventilation rate. Energy Build. 41, 190196, 2009. https://doi.org/10.1016/j.enbuild.2008.08.009 